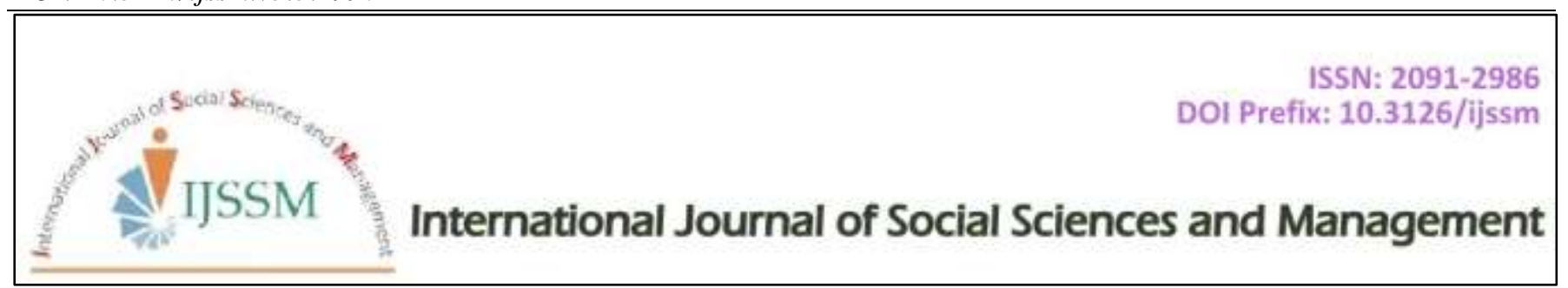

Research Article

\title{
Knowledge, Attitude and Practice Regarding Modifiable Risk Factors of Cardiovascular Diseases among Adults in Rural Community, Lahore
}

\author{
Sumaira Ejaz ${ }^{1 *}$, Muhammad Afzal ${ }^{1}$, Muhammad Hussain ${ }^{1}$, Hajra Sarwar ${ }^{1}$, Syed Amir Gilani ${ }^{2}$ \\ ${ }^{1}$ Lahore School of Nursing, The University of Lahore, Pakistan \\ ${ }^{2}$ Department of Allied Health Sciences, The University of Lahore, Pakistan
}

\begin{abstract}
Background: Cardiovascular diseases (CVD) are group of disorders of heart, blood and vessels. Major risk factors are hypertension, cigarette smoking, high fat, diabetes, obesity and physically inactive. In Pakistan, prevalence data for the Cardiovascular disease is sparse, and literature indicates that there is $30-40 \%$ of all deaths in Pakistan due to cardiovascular diseases. Objective: To assess the knowledge, attitude and practice regarding modifiable risk factors of cardiovascular diseases among adults in rural community, Lahore. Methods: This was descriptive cross-sectional study. Convenient sampling was used. Data were collected from adults of rural community Lahore. The sample size was 110. KAP questionnaire was used to collect the data. Ethical permission was obtained and data was analyzed by SPSS version 21. Results: The findings of the research were good knowledge with (67\%) high response of correct answer of "Smoking is risk factor of CVD". The attitudes were negative, $(28 \%)$ high correct response for "Do exercise for good health". The practices were very poor regarding the riskfactors of cardiovascular diseases. Conclusion: The knowledge of participants towards the risk factors of cardiovascular diseases was somehow better. The attitude was comparatively negative and practices were poor. No one was following regular exercises, dietary modifications, manage stress and smoking. Rural community people should modify their lifestyle to improve their practices. There is need for health education campaign in the rural community to minimize the risk factors of cardiovascular diseases.
\end{abstract}

Keywords: Attitude; Cardiovascular disease; Knowledge; Practice; Risk factors of cardiovascular diseases

\section{Introduction}

The Cardiovascular diseases (CVD) are group of disorders of the heart and blood vessels and they include coronary heart disease, cerebrovascular diseases, deep vein thrombosis and pulmonary embolism and some other disorders of heart (WHO, 2014). According to Texas Heart
Institute (THI) the risk-factors for cardiovascular-diseases are group into two major and minor contributing factors. Main risk factors are hypertension, cigarette smoking, high fat level, diabetes, obesity and physically inactive. The minor risk factors contain stress due to anxiety, sexhormone intake, birth-control pills and alcohol drinking. (Pagani et al., 2015). Cardiovascular diseases are the

\section{Cite this article as:}

S. Ejaz et al. (2018) Int. J. Soc. Sc. Manage. Vol. 5, Issue-3: 76-82. DOI: 10.3126/ijssm.v5i3.19902

$1 *$ Corresponding author

Sumaira Ejaz,

Lahore School of Nursing, The University of Lahore, Pakistan

Email: sumairaejaz142@gmail.com

Peer reviewed under authority of IJSSM

(C) 2018 International Journal of Social Sciences and Management

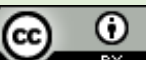

This is an open access article \& it is licensed under a Creative Commons Attribution 4.0 International License (https://creativecommons.org/licenses/by/4.0/)

Full text of this paper can be downloaded online at www.ijssm.org/ \&http://nepjol.info/index.php/IJSSM/issue/archive 
number one cause of death globally more people die annually (WHO, 2014). The WHO statistics indicate that CVD related deaths are seventeen million yearly, and this amount is gradually increasing up to twenty three million by the end of 2030 (Kumar, 2017). In Pakistan, cardiovascular diseases are also the leading cause of morbidity and mortality. Prevalence data for the Cardiovascular disease is less, thirty to forty percent of all deaths in Pakistan are the result of cardiovascular diseases (Aziz, FARUQUI, PATEL, \& JAFFERY, 2012).

The women are not only the target of this disease but also included men. In literature the risk for cardiovascular diseases are equal both in men and women (Mosca et al., 2011). Knowledge of risk factors of CVDs is crucial for every young and adult. As stated in a study, increase number of young adults have increased risk of developing cardiovascular diseases (Gaziano, Bitton, Anand, Abrahams-Gessel, \& Murphy, 2010). In this study the major modifiable risk factors are tobacco smoking, physical inactivity, unhealthy dietary intake, high cholesterol and stress. According to study conducted in Peshawar, Pakistan showed there is less knowledge regarding risk factors of cardiovascular diseases, which are lack of physical activity, excessive sugar intake, obesity, family history and stress (Zuhaid, Zahir, \& Diju, 2012).

A study reported that Pakistani young adult students have high prevalence of shisha smoking (Habibullah et al., 2013). Another modifiable risk factor is physical inactivity. The term physical inactivity is also called "sedentarism". It is the lack of physical activity (WHO, 2011). Eating fast food and carbonated drinks are also dangerous for health. In Pakistan, the prevalence of high cholesterol level is about twelve percent due to junk foods (Sherin, 2014). Stress is the minor risk factor. According to study, stress is the strain and anxiety that occur due to physical factors those are not be in a stable range (Piazza, Charles, Sliwinski, Mogle, \& Almeida, 2012).

\section{Research Questions}

Research Question 1 - What kind of knowledge rural community have regarding modifiable risk factors of cardiovascular diseases?

Research Question 2 - What kind of attitude rural community possess toward modifiable risk factors of cardiovascular diseases?

Research Question 3 - What are the preventive practices of rural community toward modifiable risks factors of cardiovascular diseases?

\section{Aims of the Study}

The purpose of the research was to assess the knowledge, attitude and practice regarding modifiable risk factors of cardiovascular diseases among adults in rural community, Lahore.

\section{Significance of the Study}

The significance of the research work is to give awareness about the modifiable risk factors of cardiovascular diseases. The benefit to the community is to reduce the burden of cardiovascular diseases. Lessen the morbidity and mortality rate. The results obtained in this study could be used by other researchers for further research study. The benefit to adults is give education and awareness of cardiovascular diseases and its risk factors. It might reduce the occurrence of disease to some extent in future.

\section{Literature Review}

According to WHO Factsheet (2017), cardiovascular diseases are the top and foremost reason for death, annually most of the people die due to cardiovascular diseases than any other disease. Moreover, in 2015 millions of people die due to cardiovascular diseases that represents $31 \%$ of deaths. Kazakh population indicates that the prevalence of cardiovascular disease risk is high and level of knowledge is less (Kulkayeva, Harun-Or-Rashid, Yoshida, Tulebayev, $\&$ Sakamoto, 2012). At International level, many countries have major causes of deaths due to risk factors of cardiovascular diseases. In Malaysia most of deaths are due to coronary heart diseases and heart attacks and ratio is higher in women than men (Ibrahim, Rahman, Rahman, \& Haque, 2016). Many respondents are associated with sedentary lifestyle, lack of exercise, poor diet, stress full life these factors are challenge for them to maintain healthy living (Kulkayeva et al., 2012).

In Middle East region, such as in Kuwait due to rapid changes in economic and due to lifestyle changes like smoking, obesity and diabetes the prevalence of cardiovascular diseases are very high (Awad \& Al-Nafisi, 2014). Asians have very high prevalence of cardiovascular diseases. In India, cardiovascular diseases are high due to risk factors include unhealthy diet, physical inactivity and tobacco smoking (Bhagyalaxmi, Atul, \& Shikha, 2013). The Attitude of respondents of rural community are bad toward cardiovascular diseases. In Contrast with study of North-East coast Malaysia (2012), where higher proportion of positive attitude were due to awareness of healthy lifestyles (Muhamad, Yahya, \& Yusoff, 2012). Tobacco smoking is the common risk factor for cardiovascular diseases. In National Academies Press Council, exposure to smoking in adults causes increase risk of heart diseases approximately 25-30\% (Council, 2010). Another study conducted in Kuwait also represent that smoking is common risk factor of heart diseases (Awad \& Al-Nafisi, 2014). 
A study in North Ireland related to knowledge of risk factors of cardiovascular diseases stated that inactivity in lifestyle is the factor of cardiovascular diseases (Al Hamarneh, Crealey, \& McElnay, 2011). In another study of Nepal respondents have lack of knowledge regarding physical inactivity which is the risk factors of cardiovascular diseases (Vaidya, Aryal, \& Krettek, 2013). However, fruit and vegetables intake are very low in rural community. These are included in unhealthy diet. In Jordanian research respondents have lack of knowledge about healthy diet (Mukattash et al., 2012). In addition, respondents take oily and fatty food excessively which causes the obesity and high cholesterol level. Stress is also an important risk factor for cardiovascular disease. The study conducted in Canada shows that the participants have less knowledge about stress (Gill \& Chow, 2010). Many respondents are associated with sedentary lifestyle, lack of exercise, poor diet, stress full life these factors are challenge for them to maintain healthy living (Kulkayeva et al., 2012).

\section{Conceptual Framework}

Conceptual Framework is given in Fig.1

\section{Methodology}

\section{Setting}

The research was conducted at Hussain Abad community, Lahore.

\section{Research Design}

The research was descriptive cross-sectional

\section{Population}

People of Hussain Abad were the target population.

\section{Sampling}

Convenient sampling technique was used. The sample was 110.

\section{Research Instrument}

An adopted questionnaire was used for this study to gather data and to answer the research questions (Ibrahim et al., 2016).

\section{Data Gathering Procedure}

A formal letter of approval was taken before starting the research. Verbal consent took from the participants.

\section{Methods used to Analyze Data}

Data was analyzed by SPSS version 21 .

\section{Study Timeline}

The study duration was September, 2017 to December, 2017.

\section{Ethical Consideration}

Ethical permission was obtained from Institutional ReviewBoard (IRB) of University of Lahore. At the household level, purpose of this study was explained to the respondents and verbal consent was taken before conducting the research.

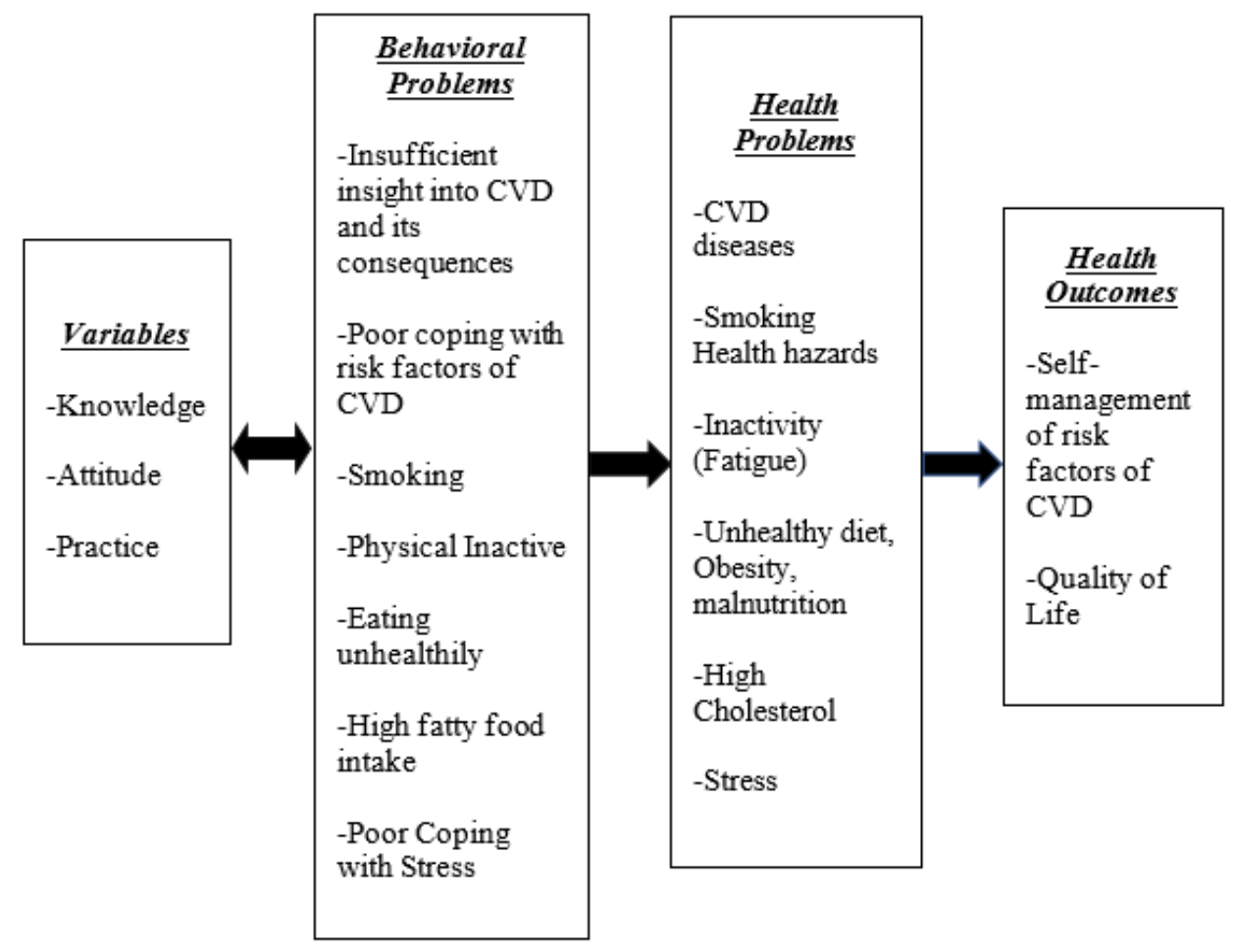

Fig 1: Model as a logic model for the needs assessment of self-managing CVD and its modifiable risk factors. (Green \& Kreuter, 1993). 


\section{Results}

\section{Socio-demographics}

In demographic, majority of were females $70 \%$ (77) and males $30 \%$ (33) respectively with mean and standard deviation of $1.7 \pm 0.46$. The mean age of the participants was 28.5 years. $35 \%, 31 \%, 21 \%, 7 \%$, and $5 \%$ of respondents were illiterate, primary, middle, secondary and some others respectively (Table 1).

\section{Knowledge Regarding Cardiovascular Disease Risk \\ Factors}

The items with higher results of correct replies were "Smoking is the risk factor of cardiovascular diseases" $(64 \%, 70)$ with mean and standard deviation of $1.13 \pm 0.59$. It is followed by "Cardiovascular-disease is related to heart and blood-vessels" $((60.9 \%, 67)$ with mean and standard deviation of $1.28 \pm 0.56$ (Table 2).

\section{Attitude Regarding Cardiovascular-Disease Risk Factors}

The answer with positive attitude was not accurately correct. However, the answer which was nearly correct was "Do exercise to maintain healthy life style" $(28 \%, 32)$ with mean and standard deviation of $3.3 \pm 1.18$. While, "Choose to use laptop but not prefer exercise" $(16 \%, 18)$ other one is "Sometime eating super late at night is good" $(11 \%, 13)$ the correct answer was Strongly Disagree. Result showed that respondents had negative attitude toward risk factors of cardiovascular diseases (Table 3 ).

\section{Practices Regarding Cardiovascular Disease Risk Factors}

In this study only 5\% (5) respondents do exercise for 10 minutes daily. The $21 \%$ (24) respondents never eat fast food. Despite that, 37\% (41) respondents do vigorous activity e.g. heavy lifting with mean and standard deviation of 3.0 \pm 0.82 . Majority of respondents had poor practices toward risk factors of cardiovascular diseases (Table 4).

Table 1: Demographic related to Age, Gender, Education

\begin{tabular}{|cc|}
\hline Age & n $(\%)$ \\
$18-23$ & $19(17.3 \%)$ \\
$24-29$ & $28(25.5 \%)$ \\
$30-35$ & $36(32.7 \%)$ \\
$36-40$ & $27(24.5 \%)$ \\
Gender & $33(30 \%)$ \\
Male & $77(70 \%)$ \\
Female & \\
Marital Status & $82(74.5 \%)$ \\
Married & $23(20.9 \%)$ \\
Unmarried & \\
Education & $40(36.4 \%)$ \\
Illiterate & $34(30.9 \%)$ \\
Primary & $23(20.9 \%)$ \\
Middle & \\
\hline
\end{tabular}

Table 2: Knowledge Regarding CVD Risk Factors ( $\mathrm{n}=110)$

\begin{tabular}{|l|l|l|l|l|}
\hline S. N. & Statements & $\begin{array}{l}\text { True } \\
\mathbf{n}(\%)\end{array}$ & $\begin{array}{l}\text { False } \\
\mathbf{n}(\boldsymbol{\%})\end{array}$ & $\begin{array}{l}\text { Don't Know } \\
\mathbf{n}(\boldsymbol{\%})\end{array}$ \\
\hline 1 & $\begin{array}{l}\text { Cardiovascular disease is related to heart and blood } \\
\text { vessels }\end{array}$ & $67(60.9)$ & $37(33.6)$ & $6(5.5)$ \\
\hline 2 & Most cardiovascular disease cases are hereditary & $48(43.6)$ & $49(44.5)$ & $13(11.8)$ \\
\hline 3 & CVD is the leading cause of death & $48(43.6)$ & $35(31.8)$ & $27(24.5)$ \\
\hline 4 & Cardiovascular disease is the disease of women only & $31(28.2)$ & $67(58.2)$ & $15(13.6)$ \\
\hline 5 & CVD can occur to young people & $35(31.8)$ & $63(57.3)$ & $12(10.9)$ \\
\hline 6 & Smoking is the risk factor of cardiovascular disease & $70(63.6)$ & $27(24.5)$ & $13(11.8)$ \\
\hline 7 & Doing house work as exercise is enough for a day & $46(41.8)$ & $41(37.3)$ & $23(20.9)$ \\
\hline 8 & If you have a slim body, you do not need to exercise & $45(40.9)$ & $47(42.7)$ & $18(16.4)$ \\
\hline 9 & $\begin{array}{l}\text { Eating fruits or vegetables is able to prevent from } \\
\text { cardiovascular diseases }\end{array}$ & $38(34.5)$ & $31(28.2)$ & $41(37.3)$ \\
\hline 10 & Irregular eating patterns has no harm on health & $45(40.9)$ & $46(41.8)$ & $19(17)$ \\
\hline 11 & $\begin{array}{l}\text { High density lipoprotein (HLP) is a good type of } \\
\text { cholesterol }\end{array}$ & $40(36.4)$ & $32(29.1)$ & $38(34.5)$ \\
\hline 12 & Prayer can help to reduce stress & $64(58.2)$ & $19(17.3)$ & $27(24.5)$ \\
\hline
\end{tabular}


Table 3: Attitude Regarding Cardiovascular Diseases Risk Factors $(n=110)$

\begin{tabular}{|l|l|l|l|l|l|l|}
\hline S. N. & Statements & $\begin{array}{l}\mathrm{S} \mathrm{D} \\
\mathrm{n}(\%)\end{array}$ & $\mathrm{D}(\%)$ & $\mathrm{n}(\%)$ & $\mathrm{n}(\%)$ & $\begin{array}{l}\mathrm{S} \mathrm{A} \\
\mathrm{n}(\%)\end{array}$ \\
\hline 1 & Smoking is bad for health & $30(27.3)$ & $23(20.9)$ & $13(11.8)$ & $18(16.4)$ & $26(23.6)$ \\
\hline 2 & Do exercise to maintain healthy life style & $3(2.7)$ & $31(28.2)$ & $20(18.2)$ & $32(29.1)$ & $24(21.8)$ \\
\hline 3 & Prefer to play with laptop instead of doing exercise & $18(16.4)$ & $21(19.1)$ & $42(38.2)$ & $22(20)$ & $7(6.4)$ \\
\hline 4 & Walking a lot can give benefits to my health & $5(4.5)$ & $34(30.9)$ & $27(24.5)$ & $35(31.8)$ & $9(8.2)$ \\
\hline 5 & Take fruits or vegetables in diet for maintaining health & $10(9.1)$ & $24(21.8)$ & $11(10)$ & $49(44.5)$ & $16(14.5)$ \\
\hline 6 & Avoid drinking carbonated drinks & $13(11.8)$ & $25(22.7)$ & $43(39.1)$ & $11(10)$ & $18(64.4)$ \\
\hline 7 & Sometime eating super late at night is good & $12(10.9)$ & $26(23.6)$ & $16(14.5)$ & $44(40)$ & $12(109)$ \\
\hline 8 & Take less oily food for healthy lifestyle & $13(11.8)$ & $28(25.5)$ & $15(13.6)$ & $36(32.7)$ & $18(16.4)$ \\
\hline 9 & Controlling stress can avoid to getting any disease & $15(13.6)$ & $30(27.3)$ & $21(19.1)$ & $33(30)$ & $11(10)$ \\
\hline 10 & I can manage my stress & $13(11.8)$ & $14(12.7)$ & $52(47.3)$ & $18(16.4)$ & $13(11.8)$ \\
\hline
\end{tabular}

Table 4: Practices Regarding Cardiovascular Diseases Risk Factors $(n=110)$

\begin{tabular}{|l|l|l|l|l|l|}
\hline S. N. & Statements & $\begin{array}{l}\text { Always } \\
\mathbf{n}(\%)\end{array}$ & $\begin{array}{l}\text { Frequently } \\
\mathbf{n}(\%)\end{array}$ & $\begin{array}{l}\text { Seldom } \\
\mathbf{n}(\%)\end{array}$ & $\begin{array}{l}\text { Never } \\
\mathbf{N}(\%)\end{array}$ \\
\hline 1 & How often do you smoke? & $33(30)$ & $18(16.4)$ & $7(6.4)$ & $52(47.3)$ \\
\hline 2 & Does your daily activity involve vigorous activity? & $2(1.8)$ & $27(24.5)$ & $41(37.3)$ & $40(36.4)$ \\
\hline 3 & Do you walk for 10minutes daily? & $5(4.5 \%)$ & $17(15.5)$ & $57(51.8)$ & $31(28.2)$ \\
\hline 4 & Do you spend your leisure time to exercise at least 20 minutes? & $9(8.2)$ & $25(22.7)$ & $36(32.7)$ & $40(36.4)$ \\
\hline 5 & How often do you take fruits in your diet? & $22(20)$ & $22(20)$ & $46(41.8)$ & $20(18.2)$ \\
\hline 6 & How often do you take vegetables in your diet? & $46(41.8)$ & $24(21.8)$ & $20(18.2)$ & $20(18.2)$ \\
\hline 7 & How often do you eat fast food? & $10(9.1)$ & $26(23.6)$ & $50(45.5)$ & $24(21.8)$ \\
\hline 8 & Do you like to eat in between main meals? e.g snaking & $8(7.3)$ & $25(22.7)$ & $39(35.5)$ & $38(34.5)$ \\
\hline 9 & Do you eat fried food as your main course? & $11(10)$ & $23(20)$. & $51(46.4)$ & $25(22.7)$ \\
\hline 10 & Do you lead a stressful life? & $35(31.8)$ & $27(24.5)$ & $24(21.8)$ & $24(21.8)$ \\
\hline
\end{tabular}

\section{Discussion}

Result showed that cardiovascular is the top and foremost reason for death in Pakistan. CVD history included topped the list hypertension, diabetes, heart attack and stroke (O'Donnell et al., 2010). There was a high possibility of occurrence of cardiovascular diseases due to hereditary but mostly due to behavior changes and sedentary styles (Abdulla \& Panza, 2009).

Respondents had better knowledge that smoking is risk factor of cardiovascular diseases. In another study, secondhand exposure to smoke causes heart diseases, which increases the risk of disease by approximately 25-30\% (Pope III et al., 2011). Moreover, the participants showed lower knowledge related to physical inactivity as risk factors when compared with study conducted in Iran (Mazloomy et al., 2014). Eating fresh fruits and vegetables keeps your heart healthy. Less intake of fibers contributes to $20.0 \%$ of heart diseases in universe. Fruit and vegetables comprises some elements that defend against cardiac diseases, stroke and hypertension (Rosamond et al., 2007). The relationship between stress and cardiovascular disease is not clear. Stress is a risk factor of cardiovascular diseases. It was identified by $64 \%$ of respondents, which is close to that study reported Jordan (Mukattash et al., 2012). The study findings showed that approximately more than half of the participants assumed that they cannot reduce their stress. Stress-management plays a vital role in controlling the different factors of cardiovascular diseases (Nekouei, Yousefy, Doost, Manshaee, \& Sadeghei, 2014). 


\section{Limitations}

This research had few limitations. First, the sample was convenient, which limited the generalizability of results to the population. In this study, women were unintentionally oversampled $(70 \%)$ because they were more likely to be available in the house when visited the home.

\section{Conclusion}

The study suggests that, level of knowledge regarding CVD is high in the rural community of Lahore, but there is no relation with the attitude and practices. The community people have negative attitude due to which practices are very poor.

\section{Acknowledgement}

Thanks to all the community members. I am thankful to Ibrahim et al., (2016), for giving me permission to use questionnaire. I am also thankful to Sir Afsar Ali as a guide for me during this research. I am much thankful to the authority of University of Lahore for all cooperation to extend this study.

\section{Reference}

Abdulla K \& Panza A (2009) Accesibility to knowledge and information on risk factors and prevention of cardiovascular diseases and preventive behaviours among the residents age 30 years and above in malemaldives. J Health Res 23: 75-80.

Al Hamarneh YN, Crealey GE \& McElnay JC (2011) Coronary heart disease: health knowledge and behaviour. International journal of clinical pharmacy 33(1): 111-123.

Awad A \& Al-Nafisi H (2014) Public knowledge of cardiovascular disease and its risk factors in Kuwait: a cross-sectional survey. BMC Public Health 14(1): 1131.

Aziz KU, Faruqui A, Patel N \& Jaffery H (2012) Prevalence and awareness of cardiovascular disease including life styles in a lower middle class urban community in an Asian country. Pakistan Heart Journal 41(34).

Bhagyalaxmi A, Atul T \& Shikha J (2013) Prevalence of risk factors of non-communicable diseases in a District of Gujarat, India. Journal of health, population, and nutrition 31(1): 78.

Council NR (2010) Secondhand smoke exposure and cardiovascular effects: making sense of the evidence: Washington, DC: The National Academies Press.

Gaziano TA, Bitton A, Anand S, Abrahams-Gessel S \& Murphy A (2010) Growing epidemic of coronary heart disease in low-and middle-income countries. Current problems in cardiology 35(2): 72-115.
Gill R \& Chow CM (2010) Knowledge of heart disease and stroke among cardiology inpatients and outpatients in a Canadian inner-city urban hospital. Canadian Journal of Cardiology 26(10): 537-541.

Green LW \& Kreuter MW (1993) Health promotion planning: An educational and ecological approach: McGraw-Hill.

Habibullah S, Ashraf J, Javed R, Naz S, Arain GM \& Akhtar T (2013) Prevalence of shisha smoking in College, University and Madarsa Students aged 2025 years in Pakistan. Pakistan Journal of Medical Research 52(1): 3 .

Ibrahim MM, Rahman NAA, Rahman NIA \& Haque M (2016) Knowledge, Attitude and Practice of Malaysian Public University Students on Risk Factors for Cardiovascular Diseases. Journal of Applied Pharmaceutical Science 6(2): 56-63.

Kulkayeva G, Harun-Or-Rashid M, Yoshida Y, Tulebayev K \& Sakamoto J (2012) Cardiovascular disease risk factors among rural Kazakh population. Nagoya journal of medical science 74(1-2): 51.

Kumar S (2017) Cardiovascular Disease and Its Determinants: Public Health Issue. Journal of Clinical Medicine and Therapeutics.

Mazloomy SS, Baghianimoghadam MH, Ehrampoush MH, Baghianimoghadam B, Mazidi, M \& Mozayan MR (2014) A study of the knowledge, attitudes, and practices (KAP) of the women referred to health centers for cardiovascular disease (CVDs) and their risk factors. Health care for women international 35(1): 50-59.

Mosca L, Benjamin EJ, Berra K, Bezanson JL, Dolor RJ, Lloyd-Jones DM and Shaw LJ (2011) Effectivenessbased guidelines for the prevention of cardiovascular disease in women-2011 update: a guideline from the American Heart Association. Circulation, CIR. 0b013e31820faaf31828.

Muhamad R, Yahya R \& Yusoff HM (2012) Knowledge, attitude and practice on cardiovascular disease among women in North-Eastcoast Malaysia. International Journal of Collaborative Research on Internal Medicine \& Public Health.

Mukattash TL, Shara M, Jarab AS, Al-Azzam SI, Almaaytah A \& Al Hamarneh YN (2012) Public knowledge and awareness of cardiovascular disease and its risk factors: a cross-sectional study of 1000 Jordanians. International Journal of Pharmacy Practice 20(6): 367-376.

Nekouei ZK, Yousefy A, Doost HTN, Manshaee G \& Sadeghei M (2014) Structural Model of 
psychological risk and protective factors affecting on quality of life in patients with coronary heart disease: A psychocardiology model. Journal of research in medical sciences: the official journal of Isfahan University of Medical Sciences 19(2): 90.

O'Donnell MJ, Xavier D, Liu L, Zhang H, Chin SL, RaoMelacini P and McQueen MJ (2010) Risk factors for ischaemic and intracerebral haemorrhagic stroke in 22 countries (the INTERSTROKE study): a casecontrol study. The Lancet 376(9735): 112-123.

Organization WH (2014) Non-communicable Diseases Country Profiles 2014.

Pagani F, Milano C, Tatooles A, Bhat G, Slaughter \& Birks E (2015) HeartWare HVAD for the treatment of patients with advanced heart failure ineligible for cardiac transplantation: results of the ENDURANCE destination therapy trial. J Heart Lung Transplant 34(4 Suppl): S9.

Piazza JR, Charles ST, Sliwinski MJ, Mogle J \& Almeida DM (2012) Affective reactivity to daily stressors and long-term risk of reporting a chronic physical health condition. Annals of Behavioral Medicine 45(1): $110-120$

Pope III CA, Burnett RT, Turner MC, Cohen A, Krewski D, Jerrett M and Thun MJ (2011) Lung cancer and cardiovascular disease mortality associated with ambient air pollution and cigarette smoke: shape of the exposure-response relationships. Environmental health perspectives 119(11): 1616.
Rosamond W, Flegal K, Friday G, Furie K, Go A, Greenlund K and Kissela B (2007) Heart disease and stroke statistics—2007 update. Circulation, 115(5), e69-e171.

Sherin A (2014) Obesity: how to prevent Pakistani people from getting heavier? Khyber Medical University Journal 5(2): 59-60.

Vaidya A, Aryal UR \& Krettek A (2013) Cardiovascular health knowledge, attitude and practice/behaviour in an urbanising community of Nepal: a populationbased cross-sectional study from Jhaukhel-Duwakot Health Demographic Surveillance Site. BMJ open 3(10): e002976.

World Health Organization Factsheet No 317 Cardiovascular Diseases [Online] Geneva: World Health Organization. 2011. Available at: http://www.who.int/mediacentre/factsheets/fs317/e n/index.html

World Health Organization: Cardiovascular diseases (CVDs): Fact sheet No. 317-Cardiovascular Disease. (Online) World Health Organization. 2017. Retrieved from http://www.who.int/mediacentre/factsheets/fs317/e $\mathrm{n} /$,

Zuhaid M, Zahir KK \& Diju IU (2012) Knowledge and perceptions of diabetes in urban and semi urban population of Peshawar, Pakistan. J Ayub Med Coll Abbottabad 24(1): 105-108. 